\title{
Low-power nuclear power plants as the most important factor of social development, development of remote and remote areas of the country and ensuring its energy security
}

\author{
Vitaliy Savelev ${ }^{1, *}$, Yuri Saraev ${ }^{2}$,Vera Bataeva $^{3}$ \\ ${ }^{1}$ AO GK Sistemy i tekhnologii, Department of science, 600014 Vladimir, Lakina st, 8, Russian Federation \\ ${ }^{2}$ AO GK Sistemy i tekhnologii, Department of science, 600014 Vladimir, Lakina st, 8, Russian Federation \\ ${ }^{3}$ Ivanovo State Power Engineering University, 153003 Ivanovo, Rabfakovskaya st., 34, Russian Federation
}

\begin{abstract}
The article is devoted to the analysis of specific requirements, problems and tasks requiring solutions for the practical application of low-power nuclear power plants, as well as their impact on the level of energy security of remote and remote regions and the country as a whole.
\end{abstract}

\section{Introduction}

Currently, there is a growing interest in small nuclear power due to its special attractiveness in social development and development of remote areas. The total capacity of low-power consumers in Russia is not less than $30 \%$ of the total generation. The number of such consumers, especially kilowatt and megawatt capacity, is in the hundreds and thousands, surpassing the number of tens and hundreds of times the number of consumers of large and medium-sized energy.

One of the main tasks to improve the territorial and production structure of the fuel and energy complex, taking into account the need to strengthen the unity of the economic space of Russia, is the development of infrastructure and facilities of the fuel and energy complex of Eastern Siberia, the Arctic zone of the Russian Federation and the Far East [1]. Social development and development of these hard-to-reach and remote areas is of strategic importance for ensuring energy and national security of Russia, as these regions are home to the main explored hydrocarbon deposits and the most important infrastructure facilities of various industries.

Priority energy consumers of these territories are [2]: - objects related to exploration, development of oil and gas fields: drilling rigs, pumps, shift camps, etc.;

- objects of the Northern sea route: port terminals, Arctic aviation, navigation and hydrographic support, meteorological services, navigation tracking systems, shipbuilding and ship repair plants;

- military facilities: observation bases of the Northern fleet, border outposts, military bases;

Consumers of low power are also large, but local energy consumers, whose energy supply is difficult economically and logistically. The principles of power supply of such consumers differ depending on the specifics of economic development of territories, working conditions and infrastructure. The total capacity of such consumers in the country is estimated at least 30 $\%$ of the total generation, and their number is estimated in the hundreds and thousands, exceeding ten times the number of consumers of large and medium-sized energy. Traditional energy supply chains have limited use for them. Therefore, the construction and development of energy supply systems of these territories should take into account their specific features in terms of energy security.

The following features are typical for the energy of the above regions [3]:

- technological isolation and inaccessibility;

- the presence of a large number of dispersed low-power energy sources;

- the disconnection of consumers of energy resources;

- absence of main interregional electric networks;

- multiple links and time restrictions on fuel delivery ("Northern delivery»);

- high cost of production of electric and thermal energy, due to the significant share of the transport component in the final cost of fuel (up to $70 \%$ );

- extremely high electricity tariffs and technical losses in the transportation of energy, as well as the need for subsidies to equalize tariffs;

- reduction in the number and critically low number of inhabitants in the territorial entities;

- capital-intensive maintenance of networks and equipment and high maintenance costs of power lines.

In view of the noted features, the risks of energy security for these territories are realized more vividly, and the consequences of their implementation can be catastrophic, since in this case it is essentially about the survivability of technological processes, about the life and health of people. To ensure the energy security of such territories, there is only one option - to have their own sources of generation.

\footnotetext{
* Corresponding author: savelev-iv@yandex.ru
} 
In Autonomous power supply systems, approximately $96 \%$ of electricity generation is accounted for by the most common energy sources for territories with decentralized power supply - diesel power plants [4]. These territories are also suitable to a certain extent for the use of renewable energy generation sources. However, their specificity creates a number of difficulties. In table. 1 the main limitations in the application of traditional sources for Autonomous systems are given.

In recent years, a new technology of production, transmission and distribution of electric and thermal energy has been actively developing all over the world. Its innovative platform is distributed generation. In a broad sense, distributed generation is considered to be those objects that are near the final consumption, regardless of who owns them. In a narrower sense, distributed generation (Distributedgeneration) is defined as the construction and operation of electric (thermal) energy sources and, if necessary, distribution networks by consumers for their own needs, as well as for the issuance of surpluses to the General electric or thermal network [5].

Table 2. Restrictions on the use of generation sources.

\begin{tabular}{|c|c|}
\hline Source type & \multicolumn{1}{|c|}{ Restrictions on the use } \\
\hline $\begin{array}{c}\text { Solar power } \\
\text { plant }\end{array}$ & \multicolumn{1}{|c|}{$\begin{array}{c}\text { Icing of solar panels and the need for } \\
\text { constant snow sweeping }\end{array}$} \\
\hline $\begin{array}{c}\text { Wind power } \\
\text { station }\end{array}$ & \multicolumn{1}{c|}{$\begin{array}{c}\text { Storm winds up to } 36 \mathrm{~m} / \mathrm{s} \text {, frost coating, } \\
\text { icing }\end{array}$} \\
\hline Diesel power \\
plant & $\begin{array}{l}\text {-only Arctic diesel fuel with a solidification } \\
\text { temperature of } 45^{\circ} \mathrm{C} \text { can be used for } \\
\text { storage, preparation and combustion in the } \\
\text { Arctic, which makes it very expensive; } \\
\text {-the cost of delivery is also high, so the cost } \\
\text { of annual "Northern delivery" (diesel fuel, } \\
\text { fuel oil, coal) costs } 500 \text { billion rubles (this is } \\
\text { 20\% of the expenditure part of the budget } \\
\text { of the Northern regions); } \\
\text {-fuel transportation costs are up to } 70 \% \text { of } \\
\text { the energy tariff; } \\
\text {-fuel is delivered only once a year and can } \\
\text { exceed the cost of fuel itself, which causes } \\
\text { huge fuel costs; } \\
\text {-the burned fuel has a negative impact on } \\
\text { the environment due to the by-products } \\
\text { released into the protected environment; } \\
\text {-high wear of generating sources. }\end{array}$ \\
\hline
\end{tabular}

In Russia, facilities that are classified as distributed generation are conventionally divided into three categories: block stations, small CHP plants in populated areas and small and medium-sized generation facilities whose owners are not electric power companies.

The growth of interest in small and medium generation is due to:

- exhaustion of a resource of a considerable part of sources of thermal and electric energy of small capacity (DES, boiler rooms, small and micro HPPs, etc.) feeding numerous Autonomous consumers;
- decrease in quality and reliability of power supply from centralized sources and constant growth of tariffs;

- the duration of restoration of power supply after technological failures and natural disasters that have become more frequent in recent years;

- constant growth in oil, gas, coal prices and fuel delivery costs.

Currently, there is a growing interest in small (AFM) and micro (ASMI) nuclear power due to its special importance in social development and development of hard-to-reach and remote areas.

Preliminary estimates show that the total need to cover the deficit of electric and thermal energy due to ACMM for the period up to 2030 is about $20 \mathrm{GW}$.

AFM is a functionally ready-to-operate module or energy capsule consisting of reactor (RU) and turbine generator sets (TSU).

ASMM reactor plant is an integrated water-water reactor of high self-protection with the following features:

- negative values of the reactivity coefficient of the core in the entire operational range of parameters;

- controlled start of the core from the critical state;

- high level of natural coolant circulation, providing effective cooling and heat removal from the core in case of design and beyond design accidents;

- high heat storage capacity of metal structures and a large mass of coolant in the reactor, providing a relatively slow flow of transients in accidents associated with a violation of the normal heat sink from the core;

- a deep-layered system of barriers to the spread of ionizing radiation and radioactive fission products of uranium into the environment, as well as the implementation of a set of technical and organizational measures to protect these barriers from internal and external influences;

- high level of reliability of security systems;

- the use of passive systems and safety devices that operate on the basis of natural processes that do not require the supply of energy from the outside;

- protection against personnel errors due to the lack of continuous maintenance of the $\mathrm{RC}$ and limited access to ITS systems.

Interindustrial creative team, organized on a voluntary basis at the LLC "Cold test Site" of the Academy of Sciences of the Republic of Sakha(Yakutia) as part of M. M. Trevgoda, JSC "SSC RF-FEI", Obninsk, A. I. Chomchoev, JSC IPH an RS (I), Yakutia, A. S. Kosoy, LEMZ, GC Almaz Antey, Moscow., I. A. Syrovatskaya, LLC Praktika, the state Duma developed the draft concept "Development of nuclear power plants of micro capacity - up to $10 \mathrm{MW"}$. (ASMI) as a factor of socio-economic development of remote and remote regions of the country". It gives a list of the main requirements for ASMM and ASMI:

- ensuring the number of hermetic barriers to the spread of radioactive fission products according to the standards and the exclusion of harmful emissions during the operation of the station;

- refusal to use partially activated fuel in ASMM;

- the use of low enriched fuel, which is important from the standpoint of non-proliferation; 
- exclusion of nuclear and radiation hazardous works with fresh spent fuel at the site of the plant installation, up to the complete exclusion of works on fuel overload at the station within the resource of its operation;

- for stations of large capacities, from a range of small capacities, for exception of works with fresh spent fuel to use two-position execution of reactor installation with combination in one block of functions of the reactor and storage without opening of the case;

the exception in the construction of the station chemically dangerous environments, and their combinations (structural materials and coolant of the reactor circuit, the working fluid of the Converter, etc.);

- reducing the power voltage of the equipment.;

- reduction of the probability of equipment failure due to improved quality of its manufacture and Assembly in the factory and transportation of ASMI equipment in the form of factory-ready units.

These and other technical solutions, in comparison with traditional high-and medium-power ASMS, should ensure the safety of ASMS at a qualitatively new level.

The presented concept was discussed with the participation of the authors of the report at a workshop of specialists in the field of nuclear energy, held at the initiative of the " International Union of veterans of nuclear energy and industry "(ICAEP) on the development of micro and small nuclear power plants (ASMI).

On it, in particular, it was noted that:

- the existing opinion that small nuclear AFMS are economically unprofitable in comparison with large power plants, as it does not take into account local conditions and the social direction of regional development.

- there is a real danger of Russia lagging behind the United States and Japan, which are working on the introduction of microreactors for civilian use.

It is known from open sources that the American company "Westinghouse" together with the Japanese company "Toshiba" are developing a line of nuclear portable microreactors "eVinci" with a capacity of 200 $\mathrm{kW}$ to $15 \mathrm{MW}$, which can be transported with a single truck;

- in the UK (in Derby) with the support of the government opened a nuclear research centre "NAMRCMidlands" for the development of small modular reactors.

- to develop regional energy supply with the use of ASM required computational design and feasibility study of ASM at the level of the Technical proposal (TP) and Feasibility study (FS) based on multivariate analysis, including social aspects and then comparing the set of parameters of different alternatives to ASM.

The meeting noted the need for:

- contact the state Corporation "Rosatom" of the Russian Federation and the Ministry of economic development, to the formation of the Program of atomic energy development for the period after 2020, the inclusion of the section "Development of nuclear power stations micromodule (ASMI) for a sustainable energy supply of remote regions of the country and their socio-economic development" with the development of the feasibility study for the development of ASM followed to be considered at STC of ROSATOM of the Russian Federation;

- JSC "SSC RF-FEI" to acquaint specialists with the draft Concept and conduct a comprehensive analysis of the demand for ASMI, as well as to develop TP and feasibility study of ASMI for specific regions, followed by consideration of TP and feasibility study at the NTS of JSC "SSC RF-FEI" and " Rosatom»;

- to recommend to administrations of separate regions to consider expediency of construction in them ASMM and to hold public discussion about possibility and expediency of introduction of ASMM at the regional level.

The use of small nuclear power is hampered by the following main reasons:

- historically established priority attention to highcapacity nuclear power plants;

- a large number of specific requirements, different application conditions, technical difficulties, strict requirements for safety and for the duration of the cycle; - impossibility of direct transfer of experience of development, creation and operation, accumulated since the beginning of development of nuclear power in the field of special nuclear power plants, etc.;

- there are restrictions on the dissemination of information on new ASMM.

\section{Conclusion}

In this article, the authors have tried to reveal the prospects of using ASMM to ensure energy security, development and development of hard-to-reach and remote regions. Mass implementation of ASMM in hardto-reach and remote areas will have a positive effect on energy security, however, the lack of real experience in the operation of ASMM in energy systems makes a correct assessment of the impact of threats to energy security at the moment in these areas impossible due to the lack of real data.

To date, the most urgent tasks are:

- ensuring the safety of ASMM taking into account the prospects of their mass introduction;

- analysis of the potential market of ASMM, requirements and conditions of selection of the most suitable types of ASMM for specific conditions of their application;

- exclusion of permanently present personnel during the operation of the station;

- automatic operation of the station while ensuring safety and self-regulation;

- remote monitoring of the station status from the centralized control panel and with the possibility of reliable automatic reactor shutdown in case of emergency situations or unauthorized interference in its operation;

- inclusion of reserve power sources in the equipment of ASMM and provision of automatic transition to them when the reactor is stopped; 
- implementation, where possible, and the inclusion of ASMM in the "smart grid" to reduce the cost of heat and electricity;

- mass implementation in remote and remote areas of the country and ensuring its energy security;

- automatic protection against natural disasters (forest fire, flood, earthquake), i.e. its automatic jamming;

- comparison of energy supply options with alternative sources of generation in remote and remote areas of the country by a set of parameters;

- assessment of the impact of commissioning of ASMM on the energy security of the regions and the country as a whole.

\section{References}

1. V.V. Bushuev, N.I. Voropai, S.M. Senderov, V.V. Saenko. About the Doctrine of energy security of Russia. Regional economy., No. 2 (30), pp. 40-50, (2012)

2. N.Yu. Kirsanov. Features of power supply of the Arctic zone of the Russian Federation. Fundamental and applied research in the modern world., No. 21, pp. 169-171, (2018)

3. V.R. Kiushkina. Optimization of local energy of decentralized territories of Northern regions through strengthening of positions of energy security (on the example of the Republic of Sakha (Yakutia))//Internet journal. Science of science., Vol. 9, No. 6, pp. 101-110, (2017)

4. D.A. Soflan, V.R. Kishkina. Problems of reliability in Autonomous power supply systems decentralized energozone. Energy. Innovation in the energy sector. CALS-technologies in the energy sector, Vol. 1, pp. 46-52, (2016)

5. D. Newslos, I.Y. Repin. Tendencies of development of distributed generation Energy, No. 7, pp. 18-25, (2012) 